\title{
Effects of processing strategy and transformation on recognition memory for photographs of faces
}

\author{
STUART J. MCKELVIE \\ Bishop's University, Lennoxville, Quebec, Canada
}

\begin{abstract}
Having judged 20 upright faces for intelligence $(n=18)$ or for spectacles $(n=14)$, subjects were given a recognition test in which half of the photographs were inverted. Accuracy was poorer for inverted photographs than for upright photographs, but the effect was only significant following intelligence judgments. It is suggested that inversion may disrupt a semantic code in memory.
\end{abstract}

Judging a face in terms of the target's personality traits, such as likability or honesty, leads to higher recognition performance than does judging it in terms of the person's sex or height (Bower \& Karlin, 1974; Mueller, Bailis, \& Goldstein, 1979). Although this result has been interpreted within the "levels of processing" framework (Bower \& Karlin, 1974; Mueller et al., 1979), with more or deeper processing giving higher scores, it has also been suggested (Winograd, 1981) that the advantage can be attributed to the likelihood that a distinctive feature is discovered. Indeed, it has been shown that processing in terms of traits or distinctive features gives a similar recognition score (Courtois \& Mueller, 1979; Winograd, 1981) and that both produce greater accuracy than do judgments of a single feature (Patterson \& Baddeley, 1977; Winograd, 1981).

Another variable exerting powerful effects is transformation by inversion, which disrupts face-recognition performance (Diamond \& Carey, 1986; Hochberg \& Galper, 1967; Yin, 1969). Competing explanations have also been offered for this effect-for example, the greater familiarity of upright faces relative to that of other objects (Goldstein \& Chance, 1981), the difficulty of retransforming many features (Rock, 1974), and a loss of expression in the inverted face (Yin, 1969, 1970). The latter interpretation implies that faces are processed, at least in part, in terms of their expression or meaning. Taken together with the levels of processing account of the effect of different initial strategies, it suggests that inversion would be particularly disruptive following "deep" encoding, compared with "shallow" encoding or to "distinctive feature" encoding. Consistent with the first prediction, McKelvie (1985) reported that judgments of liking led to higher recognition than did judgments of sex for upright faces but not for inverted faces; that is, although inversion caused a reduction in performance following both judgments, the decline was greater for liking than for sex.

I wish to acknowledge support from the Bishop's University Research Committee and to thank Patricia Monfette and Sue Waterhouse for research assistance. Send reprint requests to Stuart J. McKelvie, Department of Psychology, Bishop's University, Lennoxville, Quebec J1M 1Z7, Canada.
However, contrary to the second prediction, Valentine and Bruce (1986) found a similar effect of inversion following distinctive feature and distinctive trait judgments.

The purpose of the present experiment was to further investigate the processes underlying the effects of encoding and inversion. It was reasoned that, if initial trait processing involves isolating a distinctive feature, then it should not exceed individual feature processing if that feature was the one on which the trait judgment was based. Since it has been shown (Argyle \& McHenry, 1971) that impressions of intelligence are related to the presence of spectacles, it was predicted that recognition performance for upright faces would be similar following judgments of intelligence or of the presence of eyeglasses (in contrast to previous research comparing trait and singlefeature judgments). Also, and on the basis of Valentine and Bruce's (1986) results, it was predicted that the effect of inversion would be similar for both initial processing strategies.

\section{METHOD}

\section{Subjects}

There were 32 undergraduate student subjects assigned randomly to the intelligence $(n=18)$ and spectacles $(n=14)$ conditions, with the restriction that sex of subject was matched.

\section{Materials}

Forty black-and-white photographic slides of male and female student faces with and without spectacles (10 in each group) were used (see McKelvie, 1987, 1988). Half of the slides were designated for presentation; all were used for testing. The presentation stimuli were further divided into two sets (A and B); the distractors were divided into another two sets (C and D). On testing, half of the subjects saw Sets $A$ and $C$ upright and Sets B and D inverted, and the other half saw Sets $B$ and D upright and Sets $A$ and $C$ inverted. Within each set, half (five) of the faces wore spectacles and either two or three were males.

\section{Procedure}

The experiment was conducted in a classroom setting in two sessions corresponding to which sets were tested upright and inverted. During initial presentation, the subjects were given $7 \mathrm{sec}$ to view each of the 20 upright photographs, with exposure time controlled automatically. By circling the appropriate alternative on a prepared answer sheet, the subjects in the intelligence condition judged whether (yes) or not (no) each person looked intelligent; the subjects in the spectacles condition judged whether (yes) or not (no) each face had spectacles. Following a 5-min interval during which test sheets were given out and instruc- 
tions provided, the subjects were shown the 40 photographs for $10 \mathrm{sec}$ each and asked to judge each one as seen before (yes) or not (no). Old and new upright and inverted faces with and without spectacles were mixed randomly, with the restriction that there be a maximum of three consecutive faces from the same group. Original order of presentation was not preserved.

\section{RESULTS}

Table 1 displays the mean scores for hits, false alarms, $d^{\prime}$, and corrected hits (hits minus false alarms; see Woodworth, 1938). A $2 \times 2 \times 2$ (judgment $\times$ transformation $\times$ spectacles) analysis of variance (repeated measures on the last two factors) was conducted on each data set, with $\alpha=.05$. Degrees of freedom for all $F$ tests were 1 and 30.

Significant effects were as follows: For hits, transformation $\left[F=17.47, M S_{\mathrm{e}}=3.30\right]$ and the judgment $\times$ transformation interaction $\left[F=8.16, M S_{\mathrm{e}}=3.30\right]$; for false alarms, transformation $\left[F=45.85, M S_{\mathrm{e}}=3.47\right]$ and spectacles $\left[F=21.04, M S_{\mathrm{e}}=1.45\right]$; for $d^{\prime}$, transformation $\left[F=49.19, M S_{\mathrm{e}}=5.62\right]$, spectacles $[F=$ $\left.3.92, M S_{\mathrm{e}}=4.05, p=.054\right]$, and the judgment $\times$ transformation interaction $\left[F=12.83, M S_{\mathrm{e}}=5.62\right]$; and for corrected hits, transformation $\left[F=74.61, M S_{\mathrm{e}}=5.46\right]$, spectacles $\left[F=6.13, M S_{e}=5.72\right]$, and the judgment $\times$ transformation interaction $\left[F=8.85, M S_{\mathrm{e}}=5.46\right]$.

Table 1 shows that performance was poorer on inverted faces than it was on upright faces, but that this decline was greater following intelligence than it was following spectacles judgments. Indeed, post hoc $t$ tests demonstrated that the effect of transformation was significant only following intelligence judgments (hits: intelligence and spectacles, $t \mathrm{~s}=2.51,0.48$, respectively, $S E M=0.45$; $d^{\prime}$ : intelligence and spectacles, $t \mathrm{~s}=3.78,1.23, S E M=$ 0.59 ; and corrected hits, $t \mathrm{~s}=4.32,1.85, S E M=0.58$ ). None of the post hoc $t$ tests comparing the effects of judg-

Table 1

Means and Standard Deviations for Each Measure in Each Condition

\begin{tabular}{|c|c|c|c|c|c|c|c|c|c|}
\hline \multirow[b]{3}{*}{ Judgment } & \multirow[b]{3}{*}{$n$} & \multicolumn{4}{|c|}{ Upright } & \multicolumn{4}{|c|}{ Inverted } \\
\hline & & \multicolumn{2}{|c|}{ Spectacles } & \multicolumn{2}{|c|}{$\begin{array}{c}\text { No } \\
\text { Spectacles }\end{array}$} & \multicolumn{2}{|c|}{ Spectacles } & \multicolumn{2}{|c|}{$\begin{array}{c}\text { No } \\
\text { Spectacles }\end{array}$} \\
\hline & & $M$ & $S D$ & $M$ & $S D$ & $M$ & $S D$ & $M$ & $S D$ \\
\hline \multicolumn{10}{|c|}{ Hits } \\
\hline Intell & 18 & 4.33 & 1.03 & 4.50 & 0.71 & 3.50 & 0.71 & 3.06 & 0.9 \\
\hline Spectacles & 14 & 3.29 & 1.14 & 3.86 & 0.95 & 3.21 & 1.05 & 3.29 & \\
\hline \multicolumn{10}{|c|}{ False Alarms } \\
\hline Intel & 18 & 0.89 & 1.08 & 0.50 & 0.98 & 2.44 & 0.86 & 1.72 & 1.07 \\
\hline Spectacles & 14 & 0.86 & 0.66 & 0.50 & 0.76 & 1.79 & 1.12 & 1.29 & 0.9 \\
\hline \multicolumn{10}{|c|}{$d^{\prime}$} \\
\hline Inte & 18 & 2.90 & 1.55 & 3.11 & 1.67 & 0.64 & 0.74 & 0.90 & 1.10 \\
\hline Spectacles & 14 & 1.75 & 1.04 & 2.20 & 1.22 & 1.00 & 1.37 & 1.50 & 1.15 \\
\hline \multicolumn{10}{|c|}{ Corrected Hits } \\
\hline Intelli & 18 & 3.44 & 1.82 & 3.78 & 1.83 & 1.06 & 1.11 & 1.33 & 1. \\
\hline Spectacles & 14 & 2.43 & 1.16 & 3.36 & 1.39 & 1.43 & 1.69 & 2.00 & 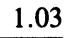 \\
\hline
\end{tabular}

Notes-For hits, false alarms, and corrected hits, maximum score was 5 . For $d^{\prime}$, maximum $=4.653$, since raw scores of 5 or 0 were converted to proportions of .99 and .01 , respectively. ment for upright or inverted faces attained significance. Performance was also generally poorer for faces with spectacles than it was without spectacles.

\section{DISCUSSION}

As expected, recognition accuracy was not significantly higher for intelligence judgments than it was for spectacles judgments on upright faces, supporting the suggestion that trait processing does not confer an advantage over feature processing when both are based on the same distinctive feature. However, contrary to the hypothesis (Winograd, 1981) that trait processing only reflects the search for a distinctive feature, the effect of inversion was not similar for both judgments. Indeed, it was larger for intelligence judgments than it was for spectacles judgments, supporting a pattern found with judgments of liking and sex (McKelvie, 1985). The latter results are consistent with the hypothesis that trait processing involves encoding faces in terms of meaning and that inversion disrupts this semantic code (McKelvie, 1985; Yin, 1969).

Before accepting this account, two other points should be noted. First, recognition accuracy on upright faces was consistently, if not significantly, higher for intelligence judgments than it was for spectacles judgments, and, contrary to a basic premise of this experiment, intelligence judgments did not reflect whether or not the faces had spectacles. Analysis of the initial judgments did not show that faces with spectacles were more likely to be judged intelligent than were those without. These observations could be interpreted as suggesting that intelligence judgments led to the isolation of distinctive features, which were not simply the presence or absence of spectacles, and that these features were less likely to be retrieved than the distinctive feature of spectacles on inverted faces. This account would preserve the distinctive feature analysis of trait effects.

It is also interesting to note that performance on faces with spectacles was generally poorer than was performance on those without. This replicates previous reports (McKelvie, 1987, 1988) and also confirms that the effect was due to false alarms rather than to hits. McKelvie suggested that spectacles may have been initially processed as a distinctive feature but subsequently only served to confuse, due to interitem similarity. From this, it might be expected that the negative effect of inversion would be smaller for faces without spectacles, since their distinctive feature would be more likely to be retrieved. However, the effects of inversion (and of the interaction between judgment and inversion) were consistent across both kinds of face.

In summary, the present experiment has demonstrated that inversion has a greater effect on recognition memory for faces following trait than does individual feature processing. Although an alternative interpretation cannot be ruled out, it is suggested that inversion may disrupt access to a semantic code.

\section{REFERENCES}

Argyle, M., \& MCHenry, R. (1971). Do spectacles really affect judgments of intelligence? British Journal of Clinical Psychology, 10, 27-29.

BowER, G. H., \& KARLIN, M. B. (1974). Depth of processing pictures of faces and recognition memory. Journal of Experimental Psychology, 103, 751-757.

Courtois, M. R., \& Mueller, J. H. (1979). Processing multiple features in facial recognition. Bulletin of the Psychonomic Society, 14, 74-76.

DiAmond, R., \& CAREY, S. (1986). Why faces are and are not special: An effect of expertise. Journal of Experimental Psychology: General, 115, 107-117.

Goldstein, A. G., \& ChANCE, J. E. (1981). Laboratory studies of face recognition. In G. Davies, H. Ellis, \& J. Shepherd (Eds.), Perceiving and remembering faces (pp. 81-104). New York: Academic Press.

HochberG, J., \& GALPER, R. E. (1967). Recognition of faces: 1. An exploratory study. Psychonomic Science, 9, 619-620.

MCKelviE, S. J. (1985). Effect of depth of processing on recognition memory for normal and inverted photographs of faces. Perceptual \& Motor Skills, 60, 503-508. 
McKelvie, S. J. (1987). Recognition memory for faces with and without spectacles. Perceptual \& Motor Skills, 65, 705-706.

McKelvie, S. J. (1988). The role of spectacles in facial memory: A replication and extension. Perceptual \& Motor Skills, 66, 651-658.

Mueller, J. H., Bailis, K. L., \& Goldstein, A. G. (1979). Depth of processing and anxiety in facial recognition. British Journal of Psychology, 70, 511-515.

Patterson, K. E., \& Baddeley, A. D. (1977). When face recognition fails. Journal of Experimental Psychology: Human Learning \& Memory, 3, 406-417.

RocK, I. (1974). The perception of disoriented figures. Scientific American, 230, 78-85.

VAlentine, T., \& Bruce, V. (1986). The effect of race, inversion and encoding activity upon face recognition. Acta Psychologica, 61, 259-273.

WINOGRAD, E. (1981). Elaboration and distinctiveness in memory for faces. Journal of Experimental Psychology: Human Learning \& Memory, 7, 181-190.

WOODWORTH, R. S. (1938). Experimental psychology. New York: Holt. YIN, R. K. (1969). Looking at upside-down faces. Journal of Experimental Psychology, 81, 141-145.

YIN, R. K. (1970). Face recognition by brain-injured patients: A dissociable ability? Neuropsychologia, 8, 395-402.

(Manuscript received July 26, 1990.) 